\title{
Quality Indicators and Outcome Measures of Endoscopy in the National Cancer Screening Program
}

\author{
Jun Ki Min ${ }^{1}$, Jae Myung Cha ${ }^{1,2}$, Min Seob Kwak ${ }^{1,2}$, Jin Young Yoon ${ }^{1,2}$, \\ Yunho Jung, Jeong Eun Shin ${ }^{4}$, and Hyo-Joon Yang ${ }^{5}$ \\ ${ }^{1}$ Department of Internal Medicine, Kyung Hee University Hospital at Gangdong, Seoul; \\ ${ }^{2}$ Department of Internal Medicine, Kyung Hee University School of Medicine, Seoul; \\ ${ }^{3}$ Department of Internal Medicine, Soonchunhyang University College of Medicine, Cheonan; \\ ${ }^{4}$ Department of Internal Medicine, Dankook University College of Medicine, Cheonan; \\ ${ }^{5}$ Department of Internal Medicine and Gastrointestinal Cancer Center, Kangbuk Samsung Hospital, \\ Sungkyunkwan University School of Medicine, Seoul, Korea.
}

Purpose: Quality indicators of the National Endoscopy Quality Improvement Program (NEQIP) and outcome measures of endoscopy in the National Cancer Screening Program (NCSP) in Korea are not clear. We evaluated the quality indicators of the revised NEQIP and outcome measures of endoscopy at different types of healthcare facilities participating in the NCSP.

Materials and Methods: This study was conducted between March and August 2018 in primary, secondary, and tertiary healthcare facilities that perform endoscopy as a part of the NCSP. Representative endoscopists completed a questionnaire for quality indicators of the NEQIP and provided data on outcome measures for endoscopy.

Results: Quality indicators of the NEQIP were mostly acceptable. However, the quality indicators for annual volume of esophagogastroduodenoscopy (EGD) and colonoscopy, training for endoscopy quality improvement by endoscopy nursing staff, colonoscopy reports, documentation of pathologic lesions, quality of endoscopy reprocessing areas, and completion of endoscopy reprocessing education programs were suboptimal. For outcome measures of EGD, the number of photo-documentations and total procedure time were higher at tertiary healthcare facilities than at other facilities ( $p<0.001$ and $p=0.023$, respectively). For the outcome measures of colonoscopy, colonoscopy completion rate and waiting times for colonoscopy were significantly higher at tertiary healthcare facilities than at other facilities (both $p<0.001$ ).

Conclusion: Outcome measures of endoscopy should be included as quality indicators of NCSP. However, universal outcome measures for all types of healthcare facilities should be established because performance levels of some outcome measures differ among individual healthcare facility types.

Key Words: Colonoscopy, gastroscopy, outcome assessment, quality indicators, mass screening

\section{INTRODUCTION}

The National Cancer Screening Program (NCSP) for gastric cancer and colorectal cancer (CRC) has been employed for Medical Aid recipients and National Health Insurance beneficiaries in the lower 50\% income bracket in Korea. ${ }^{1-4}$ In the NCSP, esophagogastroduodenoscopy (EGD) is conducted biennially for individuals aged $\geq 40$ years, ${ }^{2,3}$ whereas annual fecal immunochemical test (FIT) and confirmatory colonoscopy are performed for those aged $\geq 50$ years with positive FIT results. ${ }^{4}$

Received: May 31, 2019 Revised: August 9, 2019 Accepted: August 19, 2019

Corresponding author: Jae Myung Cha, MD, PhD, Department of Internal Medicine, Kyung Hee University Hospital at Gangdong, Kyung Hee University School of Medicine, 892 Dongnam-ro, Gangdong-gu, Seoul 05278, Korea.

Tel: 82-2-440-6113, Fax: 82-2-440-6295, E-mail: drcha@khu.ac.kr

-The authors have no potential conflicts of interest to disclose.

(C) Copyright: Yonsei University College of Medicine 2019

This is an Open Access article distributed under the terms of the Creative Commons Attribution Non-Commercial License (https://creativecommons.org/licenses/by-nc/4.0) which permits unrestricted non-commercial use, distribution, and reproduction in any medium, provided the original work is properly cited. 
Since 2009, the quality indicators of EGD and colonoscopy have been measured through the National Endoscopy Quality Improvement Program (NEQIP) of the NCSP. ${ }^{5-7}$ The NEQIP includes indicators for the qualifications of endoscopists, quality improvement for instruments available at the endoscopy unit, endoscopic process, and measurement of outcomes for endoscopy screening. ${ }^{7}$ In Western countries, the quality indicators of EGD and colonoscopy have been recently revised on the basis of updated evidence..$^{8-10}$ The NEQIP was also revised; however, many quality indicators of the NEQIP were based mostly on expert opinion and variable levels of supporting evidence. ${ }^{11}$ Therefore, whether the revised NEQIP could represent relevant quality indicators and outcome measures of EGD and colonoscopy in the NCSP is questionable. Real-world evaluation of the revised NEQIP in clinical practice may be the first step towards successful widespread adoption of the NEQIP.

In this study, we evaluated the quality indicators of the revised NEQIP and outcome measures of EGD and colonoscopy performed at primary, secondary, and tertiary healthcare facilities participating in the NCSP.

\section{MATERIALS AND METHODS}

\section{Study subjects}

This study was conducted between March and August 2018 in primary, secondary, and tertiary healthcare facilities performing screening EGD and colonoscopy as part of the NCSP. Representative endoscopists, who were all directors of endoscopy units, were selected as potential respondents to complete a questionnaire for the revised NEQIP. ${ }^{11}$ In the NCSP, EGD is conducted biennially for individuals aged $\geq 40$ years and confirmatory colonoscopy for those aged $\geq 50$ years with a positive FIT result. FIT is performed as a quantitative test, and a cutoff value of $20 \mu \mathrm{g} \mathrm{Hb} / \mathrm{g}$ feces ( $100 \mathrm{ng} \mathrm{Hb} / \mathrm{mL}$ buffer) is used as the criterion for a positive FIT result. During the study period, there was no change in the quantitative FIT analyzer, examination methods, or cut-off values. All respondents voluntarily participated in this study and prospectively collected data on the outcome measures of EGD and colonoscopy monthly during the study period. This study was approved by the Institutional Review Board of Kyung Hee University Hospital at Gangdong (KHNMC 2017-02-025).

\section{Quality indicators of the NEQIP}

Before the online survey, the representative endoscopists were instructed to assess the quality indicators of the NEQIP using documents and over one off-line meeting. The respondents were surveyed for 34 quality indicators of the NEQIP, ${ }^{11}$ and those who did not complete the questionnaire were excluded from this study. The quality indicators of the NEQIP were classified into six domains: workforce, process, facility and equipment, outcomes, reprocessing, and sedation. ${ }^{11}$ The reported completion times of the survey ranged from 30 to 40 minutes. An e-mail sur- vey was performed at 3 months after receiving instructions for the NEQIP. We sent a re-invitation e-mail to all potential respondents three times, conducted two phone calls, and sent three text messages to all non-respondents for the completion of the survey. In this study, the performance of the quality indicators was considered "optimal" when the performance level was $\geq 85 \%$ among the participants.

\section{Outcome measures of endoscopy}

In this study, all quality metrics focused on outcome measures, because outcome measures are the final target of quality improvement. The outcome measures of EGD included the number of EGDs performed per month, number of photo-documentations, total procedure time, proportion of sedative endoscopy, EGD with biopsy, precancerous/cancerous lesion (adenoma and carcinoma) detection, and EGDs with complications by month. The outcome measures of the FIT included the number of monthly FITs and proportion of positive FITs among all FITs by month. The outcome measures of colonoscopy conducted after obtaining a positive FIT result included total colonoscopy completion rate, number of monthly colonoscopies, waiting time to colonoscopy after notification of a positive FIT result, and the proportions of colonoscopies with biopsy, with advanced neoplasia (AN), which included advanced adenoma and carcinoma, and with adenoma alone. Colonoscopy completion rate was defined as the proportion of colonoscopies completed among those with a positive FIT. If the volume of colonoscopies conducted after obtaining a positive FIT result was not enough to measure the performance of colonoscopy, data on overall colonoscopies, including all diagnostic colonoscopies, were also collected. The outcome measures of the overall colonoscopies included the number of monthly overall colonoscopies, total procedure time, proportion of sedative colonoscopies, and colonoscopies with complications. In this study, complications associated with endoscopic procedures, as well as bowel preparation or sedation, were defined as any adverse events requiring endoscopic intervention or hospitalization. In this study, outcome measures of endoscopy were targeted for NEQIP of the NCSP; therefore, they were monitored at the facility level rather than the endoscopist level due to feasibility.

\section{Statistical analysis}

Descriptive statistics were used to summarize the quality indicators of the NEQIP and outcome measures of EGD and colonoscopy. Categorical data are expressed as numbers or percentages, whereas monthly continuous data are expressed as medians (ranges). One-way analysis of variance and Kruskal-Wallis test were used to compare differences in variables between three groups. All statistical tests were two-sided, and a $p$ value of $<0.05$ was considered to indicate statistical significance. Statistical analyses were performed using the Statistical Package for the Social Sciences version 18.0 for Windows (SPSS Inc., Chicago, IL, USA). 


\section{RESULTS}

We invited 17 representative endoscopists from 16 endoscopy units, and 15 of them responded for a participation rate of $88.2 \%$. The complete overall response rate was $88.2 \%$ as there were no incomplete answers. Five (33.3\%), seven (46.7\%), and three (20.0\%) of the respondents were working at primary clinics, secondary, and tertiary hospitals, respectively.

\section{Quality indicators of the NEQIP}

Table 1 shows the characteristics of the quality indicators of the NEQIP as assessed by the respondents participating in the NCSP. All respondents were gastroenterologists with fellow training of more than 1 year, had sufficient cumulative endoscopy volume, and continuous medical education (CME) for endoscopy. However, only $80 \%$ of them had optimal annual volume of EGDs $(\geq 100$ cases) and colonoscopies ( $\geq 50$ cases). Further, only $53.3 \%$ of the endoscopy units had training for endoscopy quality improvement completed by $\geq 50 \%$ of their nursing staff. While most quality indicators were optimal, the quality indicators for colonoscopy reports, documentation of pathologic lesions $(73.3 \%$ for both performance levels), the quality of reprocessing areas, and completion of endoscopy reprocessing education programs (53.3\% for both performance levels) were suboptimal.

\section{Outcome measures of EGD}

Table 2 shows the outcome measures of EGD performed in the facilities participating in the NCSP. The number of photo-documentations for EGD and total procedure time of EGD were higher at tertiary healthcare facilities than at other healthcare facilities ( $p<0.001$ and $p=0.023$, respectively). The proportion of sedative EGDs, EGDs with biopsy, precancerous/cancerous lesion detection, and EGDs with complications were not different according to healthcare facility type [ $p=$ no significance (NS)].

Table 1. Quality Indicators of the National Endoscopy Quality Improvement Program

\begin{tabular}{|c|c|c|}
\hline Domain & Quality indicators & Results \\
\hline Workforce & $\begin{array}{l}\text { Specialized endoscopist (specialists with supervised training } \geq 1 \text { year and EGD experience } \geq 500 \text { cases) } \\
\text { Specialized endoscopist (specialists with supervised training } \geq 1 \text { year and colonoscopy experience } \geq 150 \text { cases) } \\
\text { Volume of EGDs ( } \geq 300 \text { cases } / 3 \text { years) } \\
\text { Volume of colonoscopies ( } \geq 150 \text { cases } / 3 \text { years) } \\
\text { CME for endoscopy ( } \geq 12 \text { hours/3 years) } \\
\text { Training for endoscopy quality improvement completed by } \geq 50 \% \text { of nursing staff }\end{array}$ & $\begin{array}{l}15(100.0) \\
15(100.0) \\
12(80.0) \\
12(80.0) \\
15(100.0) \\
8(53.3)\end{array}$ \\
\hline Process & $\begin{array}{l}\text { Use of a pre-procedure checklist } \\
\text { Education on bowel preparation for colonoscopy } \\
\text { Informed consent for colonoscopy } \\
\text { Photo-documentation for EGD (excellent) } \\
\text { Photo-documentation for colonoscopy (excellent) } \\
\text { Average withdrawal time } \geq 6 \text { minutes in negative-result colonoscopy } \\
\text { Instruction for the post-procedure precautions after EGD } \\
\text { Instruction for the post-procedure precautions after colonoscopy } \\
\text { Labelling tissue sample }\end{array}$ & $\begin{array}{l}15(100.0) \\
15(100.0) \\
15(100.0) \\
15(100.0) \\
15(100.0) \\
13(86.7) \\
14(93.3) \\
14(93.3) \\
15(100.0)\end{array}$ \\
\hline Facilities and equipment & $\begin{array}{l}\text { Endoscopy unit separate from the outpatient clinic } \\
\text { Available equipment for adverse events }\end{array}$ & $\begin{array}{l}15(100.0) \\
15(100.0)\end{array}$ \\
\hline Outcome & $\begin{array}{l}\text { Quality of EGD report (excellent) } \\
\text { Quality of colonoscopy report (excellent) } \\
\text { Quality of documentation of pathologic lesion (excellent) } \\
\text { Helicobacter pylori infection test for peptic ulcers } \\
\text { Frequency of adequate bowel preparation of } \geq 85 \%\end{array}$ & $\begin{array}{l}13(86.7) \\
11(73.3) \\
11(73.3) \\
15(100.0) \\
14(93.3)\end{array}$ \\
\hline Reprocessing & $\begin{array}{l}\text { Use of standard protocols } \\
\text { Quality of reprocessing procedures (excellent) } \\
\text { Use of high-level disinfectants } \\
\text { Compliance of reprocessing guideline (excellent) } \\
\text { Use of disposable product or sterilization for reuse } \\
\text { Use of personal protective equipment } \\
\text { Quality of reprocessing area (excellent) } \\
\text { Quality of endoscope storage (excellent) } \\
\text { Completion of endoscopy reprocessing education programs (excellent) }\end{array}$ & $\begin{array}{c}13(86.7) \\
13(86.7) \\
14(93.3) \\
13(86.7) \\
15(100.0) \\
13(86.7) \\
8(53.3) \\
13(86.7) \\
8(53.3)\end{array}$ \\
\hline Sedation & $\begin{array}{l}\text { Pre-sedation risk assessment and sedation-specific informed consent (excellent) } \\
\text { Optimal monitoring and recording of sedation } \\
\text { Use of a standardized discharge scoring system }\end{array}$ & $\begin{array}{l}15(100.0) \\
14(93.3) \\
14(93.3)\end{array}$ \\
\hline
\end{tabular}

EGD, esophagogastroduodenoscopy; CME, continuous medical education.

Data are expressed as number (\%). 


\section{Outcome measures of colonoscopy}

Table 3 shows the outcome measures of colonoscopies performed in the facilities participating in the NCSP. The colonoscopy completion rate, number of monthly colonoscopies conducted after obtaining positive FIT results in the NCSP, and waiting time to colonoscopy were significantly higher at tertiary healthcare facilities (all $p<0.001$ ). The proportion of positive FITs, colonoscopies with biopsy, colonoscopies with AN, colonoscopies with adenoma, total procedure time of overall colonoscopies, and proportions of sedative colonoscopies and colonoscopies with complications were not different according to healthcare facility type $(p=\mathrm{NS})$.

\section{DISCUSSION}

This is the first study to investigate quality indicators of the NEQIP and outcome measures of endoscopy in the NCSP according to healthcare facility type in Korea. Among the quality indicators of the NEQIP, most were close to optimal; however, the quality indicators for annual volume of EGD and colonoscopy, training for endoscopy quality improvement by endoscopy nursing staff, colonoscopy reports, documentation of pathologic lesions, quality of endoscopy reprocessing areas, and completion of endoscopy reprocessing education programs were not adequate.

In the NEQIP, the recommended annual volume of EGD and colonoscopy cases are 100 and 50, respectively. ${ }^{11}$ No consensus is reported on the minimum number of annual EGDs, where-

Table 2. Outcome Measures of EGD in the National Cancer Screening Program

\begin{tabular}{lcccc}
\hline \multicolumn{1}{c}{ Outcome measures } & $\begin{array}{c}\text { Primary healthcare } \\
\text { facility }(\mathbf{n}=\mathbf{5})\end{array}$ & $\begin{array}{c}\text { Secondary healthcare } \\
\text { facility }(\mathbf{n}=\mathbf{7})\end{array}$ & $\begin{array}{c}\text { Tertiary healthcare } \\
\text { facility }(\mathbf{n}=\mathbf{3})\end{array}$ & $\boldsymbol{p}$ value \\
\hline Total number of EGDs & 2614 & 32983 & 8302 & \\
Number of monthly EGDs/endoscopy unit & $78.5(30-226)$ & $1013(352-1690)$ & $465(311-557)$ & $<0.001$ \\
Number of photo-documentations/EGD & $33(22.0-38.0)$ & $28(16.0-37.0)$ & $48.5(29.0-68.0)$ & $<0.001$ \\
Total procedure time/EGD (min) & $3.2(2.1-4.0)$ & $3.3(2.0-6.0)$ & $4.0(3.0-6.0)$ & 0.023 \\
Proportion of sedative EGD (\%) & $64.4(24.2-89.1)$ & $41.8(10.3-96.2)$ & $42.9(35.3-51.3)$ & 0.441 \\
Proportion of EGD with biopsy (\%) & $72.5(10.6-97.6)$ & $13.4(3.3-44.5)$ & $40.2(13.7-60.7)$ & 0.313 \\
Proportion of precancerous/cancerous lesion detection (\%) & $1.1(0.0-4.4)$ & $0.2(0.0-1.8)$ & $0.5(0.2-1.8)$ & 0.183 \\
Proportion of EGDs with complications (\%) & $0.0(0.0-0.9)$ & $0.0(0.0-1.3)$ & $0.0(0.0-0.2)$ & 0.663 \\
\hline
\end{tabular}

EGD, esophagogastroduodenoscopy.

Continuous data are expressed as median (range).

Table 3. Outcome Measures of Colonoscopy in the National Cancer Screening Program

\begin{tabular}{|c|c|c|c|c|}
\hline Outcome measures & $\begin{array}{l}\text { Primary healthcare } \\
\text { facility }(n=5)\end{array}$ & $\begin{array}{l}\text { Secondary healthcare } \\
\text { facility }(n=7)\end{array}$ & $\begin{array}{l}\text { Tertiary healthcare } \\
\text { facility }(\mathrm{n}=3)\end{array}$ & $p$ value \\
\hline \multicolumn{5}{|l|}{ Outcome measure for FIT } \\
\hline Number of FITs & 1870 & 21576 & 7981 & \\
\hline Number of monthly FITs & $66(28-110)$ & 720 (102-1048) & $453.5(151-550)$ & $<0.001$ \\
\hline Proportion of positive FITs (\%) & $3.0(0.0-24.3)$ & $3.0(0.4-40.2)$ & $3.1(1.0-8.0)$ & 0.205 \\
\hline \multicolumn{5}{|l|}{ Outcome measure of colonoscopy with positive FIT results } \\
\hline Number of colonoscopies & 71 & 948 & 245 & \\
\hline Colonoscopy completion rate (\%) & 70.3 & 54.1 & 98.4 & $<0.001$ \\
\hline Number of monthly colonoscopies & $1(0-20)$ & $7(1-145)$ & $8.5(1-42)$ & $<0.001$ \\
\hline Waiting time to colonoscopy (day) & $10.5(1-74)$ & $25.0(1-91)$ & $45.0(1-64)$ & $<0.001$ \\
\hline Proportion of colonoscopies with biopsy (\%) & $3.0(0.0-24.3)$ & $3.0(0.4-40.2)$ & $3.1(1.0-8.0)$ & 0.430 \\
\hline Proportion of colonoscopies with AN (\%) & $0.0(0.0-100.0)$ & $9.5(0.0-100.0)$ & $13.3(0.0-100.0)$ & 0.565 \\
\hline Proportion of colonoscopies with adenoma (\%) & $50.0(0.0-100.0)$ & $41.6(0.0-100.0)$ & $42.2(17.4-100.0)$ & 0.106 \\
\hline \multicolumn{5}{|l|}{ Outcome measure of overall colonoscopies* } \\
\hline Number of colonoscopies & 1309 & 25194 & 7177 & \\
\hline Number of monthly colonoscopies & $37.5(8-127)$ & $518(97-2,262)$ & $399.0(129-659)$ & $<0.001$ \\
\hline Total procedure time (min) & $11.5(5.5-29.0)$ & $12.5(6.0-22.0)$ & $12.0(6.0-23.0)$ & 0.959 \\
\hline Proportion of sedative colonoscopies (\%) & $93.5(75.0-100.0)$ & $87.4(8.7-100.0)$ & $88.6(82.8-96.9)$ & 0.306 \\
\hline Proportion of colonoscopies with complications (\%) & $0.0(0.0-4.4)$ & $0.0(0.0-0.9)$ & $0.0(0.0-2.1)$ & 0.448 \\
\hline
\end{tabular}

FIT, fecal immunochemical test; AN, advanced neoplasia.

Continuous data are expressed as median (range).

*Overall colonoscopy includes all diagnostic colonoscopies. 
as 150-200 annual colonoscopies are recommended in guidelines. ${ }^{10,12}$ The European Society of Gastrointestinal Endoscopy (ESGE) recommends a minimum number of annual colonoscopies to be performed. ${ }^{10}$ The National Health Service Bowel Cancer Screening Programme of the United Kingdom and the Spanish Society of Gastrointestinal Endoscopy recommend at least 150 and 200 annual colonoscopies for their respective National CRC Screening Programs. ${ }^{10}$ Harewood ${ }^{13}$ reported an annual volume of at least 200 colonoscopies are required to maintain adequate competence among junior endoscopists. Considering suboptimal levels in the annual volumes of endoscopies in the present study, quality improvement programs may be advised to focus on low-volume endoscopists and endoscopy units. The US guidelines have suggested CME to maintain proficiency for endoscopists and endoscopy nursing staff, ${ }^{14,15}$ however, education for the latter was not adequate in the NEQIP. Therefore, CME should be emphasized for the endoscopy nursing staff in the NCSP.

As the quality of endoscopy is closely associated with the quality of the endoscopy report, accurate endoscopy reporting is one of the main goals of the NEQIP. ${ }^{11,16}$ The endoscopy report helps to exchange information on endoscopic findings, treatments, clinical recommendations, and adverse effects. ${ }^{17,18}$ Suboptimal performance for colonoscopy reports and documentation of pathologic lesions in the NEQIP may be associated with a lack of awareness of the importance of accurate endoscopy reports and high endoscopy workloads in daily clinical practice. However, it is not easy to demonstrate a negative association between high endoscopy workloads and poor reports/documentations of colonoscopy because their objective measurement is difficult. In the reprocessing domain, the endoscopy examination area should be separated from the reprocessing area, because completely sterilized endoscopes may be re-contaminated during storage. ${ }^{19,20}$ In the NEQIP, over $50 \%$ of endoscopists and reprocessing personnel are required to complete endoscopy reprocessing education programs. ${ }^{11}$ The suboptimal performance level for the quality of reprocessing areas and completion of endoscopy reprocessing education programs in the NEQIP may be associated with a lack of training in infection control and poor infrastructure for primary clinics.

For the outcome measures of EGD, the number of photo-documentations and total procedure times of EGD were significantly higher at tertiary healthcare facilities. The recommended minimum numbers of photo-documentations for EGD are 10 according to an ESGE quality improvement initiative ${ }^{17}$ and 8 according to the NEQIP, respectively. ${ }^{11}$ In this regard, the number of photo-documentations for EGD was excellent regardless of healthcare facility type in the current study. The total procedure time of EGD was also suggested as a potential quality indicator of EGD. ${ }^{17}$ It could be a outcome measure of EGD, which is comparable to the withdrawal time of colonoscopy; however, it is based only on limited evidence, and the cutoff procedure time varied from 3 to 7 minutes for EGD. ${ }^{21-23}$ Biopsy rate could be con- sidered as a quality indicator of EGD, as it has been shown to be associated with efficacy in gastric premalignant conditions, as well as with the rate of missed gastric cancers. ${ }^{24}$ However, it was not different among the different healthcare facility types. Precancerous/cancerous lesion detection rates in EGD could also be an important performance measure. However, no agreement has been reached on a specific cutoff for the detection of precancerous/cancerous lesions in the NEQIP because of inconsistency in supporting evidence. ${ }^{11}$ Furthermore, the proportions of EGDs with precancerous/cancerous lesions did not differ according to healthcare facility type. As the number of cases of precancerous/cancerous lesion was to small to analyze associations with total procedure time, biopsy, or photo-documentation, further larger studies are needed.

Regarding the outcome measures of colonoscopy, the colonoscopy completion rate and waiting time to colonoscopy were significantly higher at tertiary healthcare facilities. In US guidelines, ${ }^{25}$ the colonoscopy completion rate for those with a positive FIT should be more than $80 \%$. In this regard, colonoscopy completion rate was only optimal at tertiary healthcare facilities in the current study. However, our results should cautiously be interpreted because colonoscopy could be performed at the cost of oneself(i.e., outside of NCSP) at primary and secondary healthcare facilities when participants had a positive FIT. Colonoscopy registry with a tracking system may be able to increase colonoscopy completion rates for those with a positive FIT. The waiting time to colonoscopy after obtaining a positive FIT result was 39.7 days in our previous study. ${ }^{26} \mathrm{~A}$ Spanish working group recommends an optimal waiting time to colonoscopy of less than 42 days. ${ }^{12}$ In a microsimulation model, ${ }^{27} 12$ months of waiting time to colonoscopy after obtaining a positive FIT result can yield proportional losses of screening benefits, according to a study in the US. In addition, longer waiting time for colonoscopy after obtaining a positive FIT result has been shown to be associated with an increased risk of neoplasia. ${ }^{28}$ However, waiting time for colonoscopy after a positive FIT is not an important issue in Korea, because median waiting times to colonoscopy are less than 45 days (1.5 months) regardless of healthcare facility type. The most important measure of FIT-based screening may be the AN detection rate; however, it was not suggested as a quality indicator in US guidelines owing to the low likelihood of those findings and the progressive reduction in those findings with subsequent series of FITs. ${ }^{25}$ The US guidelines suggested a 35-45\% adenoma detection by colonoscopy as an outcome measure. ${ }^{25}$ In this regard, the outcome measure of the current study may be optimal, as the median proportions of colonoscopies with adenoma ranged from 41.6-50.0\% regardless of healthcare facility type. The positive rate of FIT results was also suggested as a potential quality metrics for $\mathrm{FIT}^{29}$ however, the proportion of positive FITs did not significantly differ according to healthcare facility type in this study.

Our study results need to be interpreted with caution in the context of potential limitations. The generalizability of the study 
results may be limited, owing to selection bias of the survey respondents, as they were all gastroenterologists and completed gastrointestinal fellowship training. In addition, our results may not be generalizable to other endoscopists who do not perform endoscopy in the NCSP. A larger survey from variable endoscopy settings may be warranted to overcome this limitation. Furthermore, the sample size was small. It was very difficult to enroll a large enough number of physicians who are willing to provide endoscopy quality data for the NCSP. Our respondents were representative endoscopists of each endoscopy units and presented actual clinical setting data in the NCSP. Previous studies based on the NCSP were limited by retrospective data collection, which is inaccurate, biased, and not representative of daily clinical practice. However, our data collection has minimal bias as the participating respondents fully agreed with the aim and the design of our study and collected data. Therefore, our findings reflect important NCSP data, despite the small sample size. The performance level of outcome measures was considered as "optimal" when the performance level was $\geq 85 \%$ among the participants in this study. However, there is no standard threshold of an optimal performance, which makes our definition arbitrary. Furthermore, outcome measures were monitored at the facility level rather than at the endoscopist level in this study. Considering the feasibility and reliability of quality metrics in the NCSP, since many endoscopists do not have adequate numbers of quality events to support reliable quality measurement, measurement at the facility level should be considered. ${ }^{30}$

In conclusion, outcome measures of endoscopy should be included as quality indicators of NCSP. However, universal outcome measures for all types of healthcare facilities should be established because performance levels of some outcome measures were different in each healthcare facility type.

\section{ACKNOWLEDGEMENTS}

This study was supported by a National Cancer Center grant (1560460-1).

We would like to thank Hyejin Ki, Jongcheol Kim, Jungsun Yoo, Wooyoung Heo, In-taik Hong, A Ri Shin, Jae Kyoung Shin, Hyae Min Lee, Yong Sung Choi, Wan Jung Kim, and Yong Jae Han for collecting study data.

\section{AUTHOR CONTRIBUTIONS}

Conceptualization: Jae Myung Cha. Data curation: Jun Ki Min, Yunho Jung, Jeong Eun Shin. Formal analysis: Jae Myung Cha. Funding acquisition: Jae Myung Cha. Investigation: Jae Myung Cha. Methodology: Jae Myung Cha, Jin Young Yoon. Project administration: Jae Myung Cha. Resources: Jun Ki Min, Yunho Jung, Jeong Eun Shin. Software: Min Seob Kwak. Supervision: Jae Myung Cha. Validation: Jae Myung Cha. Visualization: Jae Myung Cha, Jun Ki Min. Writingoriginal draft: Jun Ki Min, Jae Myung Cha, Min Seob Kwak, Jin Young Yoon, Yunho Jung, Jeong Eun Shin, Hyo-Joon Yang. Writing-review \& editing: Jae Myung Cha, Jun Ki Min.

\section{ORCID iDs}

Jun Ki Min https://orcid.org/0000-0003-0354-855X

Jae Myung Cha https://orcid.org/0000-0001-9403-230X

Min Seob Kwak https://orcid.org/0000-0002-8988-7423

Jin Young Yoon https://orcid.org/0000-0002-5280-0443

Yunho Jung https://orcid.org/0000-0002-7760-0050

Jeong Eun Shin https://orcid.org/0000-0001-5706-3967

Hyo-Joon Yang https://orcid.org/0000-0002-0265-672X

\section{REFERENCES}

1. Jun JK, Choi KS, Lee HY, Suh M, Park B, Song SH, et al. Effectiveness of the Korean National Cancer Screening Program in reducing gastric cancer mortality. Gastroenterology 2017;152:1319-28.

2. Choi KS, Jun JK, Park EC, Park S, Jung KW, Han MA, et al. Performance of different gastric cancer screening methods in Korea: a population-based study. PLoS One 2012; 7:e50041.

3. Lee S, Jun JK, Suh M, Park B, Noh DK, Jung KW, et al. Gastric cancer screening uptake trends in Korea: results for the National Cancer Screening Program from 2002 to 2011: a prospective cross-sectional study. Medicine (Baltimore) 2015;94:e533.

4. Shin A, Choi KS, Jun JK, Noh DK, Suh M, Jung KW, et al. Validity of fecal occult blood test in the National Cancer Screening Program, Korea. PLoS One 2013;8:e79292.

5. Cha JM, Han DS, Lee HL, Kim YH, Chung IK, Kim HS, et al. Endoscopist specialty is associated with high-quality endoscopy in Korea. Yonsei Med J 2012;53:310-7.

6. Cha JM, Moon JS, Chung IK, Kim JO, Im JP, Cho YK, et al. National Endoscopy Quality Improvement Program remains suboptimal in Korea. Gut Liver 2016;10:699-705.

7. Cho YK. How to improve the quality of screening endoscopy in Korea: National Endoscopy Quality Improvement Program. Clin Endosc 2016;49:312-7.

8. Park WG, Shaheen NJ, Cohen J, Pike IM, Adler DG, Inadomi JM, et al. Quality indicators for EGD. Am J Gastroenterol 2015;110:60-71.

9. Rex DK, Schoenfeld PS, Cohen J, Pike IM, Adler DG, Fennerty MB, et al. Quality indicators for colonoscopy. Am J Gastroenterol 2015; 110:72-90.

10. Rembacken B, Hassan C, Riemann JF, Chilton A, Rutter M, Dumonceau JM, et al. Quality in screening colonoscopy: position statement of the European Society of Gastrointestinal Endoscopy (ESGE). Endoscopy 2012;44:957-68.

11. Min JK, Cha JM, Cho YK, Kim JH, Yoon SM, Im JP, et al. Revision of quality indicators for the Endoscopy Quality Improvement Program of the National Cancer Screening Program in Korea. Clin Endosc 2018;51:239-52.

12. Jover R, Herráiz M, Alarcón O, Brullet E, Bujanda L, Bustamante M, et al. Clinical practice guidelines: quality of colonoscopy in colorectal cancer screening. Endoscopy 2012;44:444-51.

13. Harewood GC. Relationship of colonoscopy completion rates and endoscopist features. Dig Dis Sci 2005;50:47-51.

14. ASGE Standards of Practice Committee, Jain R, Ikenberry SO, Anderson MA, Appalaneni V, Ben-Menachem T, Decker GA, et al. Minimum staffing requirements for the performance of GI endoscopy. Gastrointest Endosc 2010;72:469-70.

15. American Society for Gastrointestinal Endoscopy. Quality improvement of gastrointestinal endoscopy: guidelines for clinical application. Gastrointest Endosc 1999;49:842-4.

16. Bisschops R, Areia M, Coron E, Dobru D, Kaskas B, Kuvaev R, et al. Performance measures for upper gastrointestinal endoscopy: $\mathrm{a}$ European Society of Gastrointestinal Endoscopy (ESGE) Quality Im- 
provement Initiative. Endoscopy 2016;48:843-64.

17. Bretthauer M, Aabakken L, Dekker E, Kaminski MF, Rösch T, Hultcrantz R, et al. Requirements and standards facilitating quality improvement for reporting systems in gastrointestinal endoscopy: European Society of Gastrointestinal Endoscopy (ESGE) Position Statement. Endoscopy 2016;48:291-4.

18. Kaminski MF, Thomas-Gibson S, Bugajski M, Bretthauer M, Rees CJ, Dekker E, et al. Performance measures for lower gastrointestinal endoscopy: a European Society of Gastrointestinal Endoscopy (ESGE) Quality Improvement Initiative. Endoscopy 2017;49:378-97.

19. Reprocessing Guideline Task Force, Petersen BT, Cohen J, Hambrick RD 3rd, Buttar N, Greenwald DA, Buscaglia JM, et al. Multisociety guideline on reprocessing flexible GI endoscopes: 2016 update. Gastrointest Endosc 2017;85:282-94.

20. Herrin A, Loyola M, Bocian S, Diskey A, Friis CM, Herron-Rice L, et al. Standards of infection prevention in reprocessing flexible gastrointestinal endoscopes. Gastroenterol Nurs 2016 39:404-18.

21. Teh JL, Tan JR, Lau LJ, Saxena N, Salim A, Tay A, et al. Longer examination time improves detection of gastric cancer during diagnostic upper gastrointestinal endoscopy. Clin Gastroenterol Hepatol 2015;13:480-7.

22. Park JM, Huo SM, Lee HH, Lee BI, Song HJ, Choi MG. Longer observation time increases proportion of neoplasms detected by esophagogastroduodenoscopy. Gastroenterology 2017;153:460-9.

23. Kawamura T, Wada H, Sakiyama N, Ueda Y, Shirakawa A, Okada Y, et al. Examination time as a quality indicator of screening upper gastrointestinal endoscopy for asymptomatic examinees. Dig En- dosc 2017;29:569-75.

24. Januszewicz W, Wieszczy P, Bialek A, Karpinska K, Szlak J, Szymon$\mathrm{ik} \mathrm{J,} \mathrm{et} \mathrm{al.} \mathrm{Endoscopist} \mathrm{biopsy} \mathrm{rate} \mathrm{as} \mathrm{a} \mathrm{quality} \mathrm{indicator} \mathrm{for} \mathrm{outpa-}$ tient gastroscopy: a multicenter cohort study with validation. Gastrointest Endosc 2019;89:1141-9.

25. Robertson DJ, Lee JK, Boland CR, Dominitz JA, Giardiello FM, Johnson DA, et al. Recommendations on fecal immunochemical testing to screen for colorectal neoplasia: a consensus statement by the US Multi-Society Task Force on Colorectal Cancer. Gastroenterology 2017;152:1217-37.

26. Kim DH, Cha JM, Kwak MS, Yoon JY, Cho YH, Jeon JW, et al. Quality metrics of a fecal immunochemical test-based colorectal cancer screening program in Korea. Gut Liver 2018;12:183-9.

27. Meester RG, Zauber AG, Doubeni CA, Jensen CD, Quinn VP, Helfand $\mathrm{M}$, et al. Consequences of increasing time to colonoscopy examination after positive result from fecal colorectal cancer screening test. Clin Gastroenterol Hepatol 2016;14:1445-51.

28. Gellad ZF, Almirall D, Provenzale D, Fisher DA. Time from positive screening fecal occult blood test to colonoscopy and risk of neoplasia. Dig Dis Sci 2009;54:2497-502.

29. Shin HY, Suh M, Baik HW, Choi KS, Park B, Jun JK, et al. Performance of the fecal immunochemical test for colorectal cancer screening using different stool-collection devices: preliminary results from a randomized controlled trial. Gut Liver 2016;10:925-31.

30. Scholle SH, Roski J, Adams JL, Dunn DL, Kerr EA, Dugan DP, et al. Benchmarking physician performance: reliability of individual and composite measures. Am J Manag Care 2008;14:833-8. 